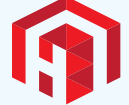 Heighten Science \\ P U B L I C I T I O N S Corporation \\ ISSN \\ 2575-0143}

\title{
Diagnostic accuracy of TIMI versus GRACE score for prediction of death in patients presenting with Acute Non-ST Elevation Myocardial Infarction (NSTEMI)
}

\author{
Syed Haseeb Raza Naqvi ${ }^{1}$, Tariq Abbas ${ }^{1}$, Han Naung Tun ${ }^{2 *}$, Ali \\ Ahmad Naqvi ${ }^{1}$, Zubair Zaffar ${ }^{1}$, Badar ul Ahad Gill ${ }^{1}$ and Nisar \\ Ahmad $^{1}$ \\ ${ }^{1} \mathrm{CPE}$ Institute of Cardiology, Multan, Punjab, Pakistan \\ ${ }^{2}$ Clinical and Research Working Groups, European Society of Cardiology, Sophia Antipolis, France
}

\footnotetext{
*Address for Correspondence: Han Naung Tun, Clinical and Research Working Groups, European Society of Cardiology, Sophia Antipolis, France, Email: annasxhan@gmail.com

Submitted: 14 February 2019

Approved: 21 February 2019

Published: 22 February 2019
}

Copyright: ๑ 2019 Naqvi SHR, et al. This is an open access article distributed under the Creative Commons Attribution License, which permits unrestricted use, distribution, and reproduction in any medium, provided the original work is properly cited

Keywords: TIMI; GRACE; Cardiac; Infarction; Acute; Risk; Elevation

Check for updates

\section{Abstract}

Background: Acute Coronary Syndrome describes a spectrum of disease ranging from unstable angina through non-ST-Elevation Myocardial Infarction (NSTEMI) to ST-Elevation Myocardial Infarction (STEMI). Early death in NSTEMI is usually due to an arrhythmia. Patients should be admitted immediately to hospital, preferably to a cardiac care unit because there is a significant risk of death.

Objective: To compare the diagnostic accuracy of TIMI versus GRACE for prediction of death in patients presenting with Acute Non-ST elevation Myocardial Infarction

Material \& Methods: This present cross sectional study was conducted at Department of Cardiology, CPEIC, Multan. All patients assessed according to given scores in the two scoring system i.e. TIMI risk score and GRACE score. Then patients were labeled as high or low risk for death. Data was collected by using pre-designed proforma. $2 \times 2$ tables were generated to measure the sensitivity, specificity, positive predictive value, negative Predictive value and diagnostic accuracy of TMI Risk score and GRACE Score for prediction of death in NSTEMI patients.

Results: In our study the mean age of the patients was $55.73 \pm 9.78$ years. The male to female ratio of the patients was 1.6:1. The diabetes as risk factor was found in $145(39 \%)$ patients, smoking as risk factor was found in $53(14.2 \%)$ patients and hypertension as risk factor was found in $174(46.8 \%)$ patients. the sensitivity of TIMI risk was $97.7 \%$ with specificity of $92.93 \%$ and the diagnostic accuracy was $95.16 \%$, similarly the sensitivity of GRACE risk was $100 \%$ with specificity of $95.96 \%$ and the diagnostic accuracy was $97.85 \%$.

Conclusion: Our study results concluded that both the TIMI risk and GRACE risk are good predictor of death in patients presenting with Acute Non-ST elevation Myocardial Infarction with higher sensitivity and diagnostic accuracy. However the GRACE risk showed more accurate results as compared to TIMI risk.

\section{Introduction}

Acute Coronary Syndrome describes a spectrum of disease ranging from unstable angina through non-ST-Elevation Myocardial Infarction (NSTEMI) to ST-Elevation Myocardial Infarction (STEMI). The 6months mortality rates in global registry of Acute Coronary Events (GRACE) were 13\% for patients with NSTEMI and 8\% for those with unstable angina and 30 day mortality was $9.1 \%$ despite the best conventional therapy $[1,2]$.

All patients with Unstable Angina and NSTEMI should undergo risk stratification soon after presentation. The Thrombolysis in Myocardial Infarction (TIMI) risk score, 
Global Registry of Acute Coronary Events (GRACE) risk index and Platelet glycoprotein IIb/IIIa in Unstable angina [3]. TIMI and GRACE are the risk scores that up until now have been most extensively investigated, with GRACE performing better. There are other potentially useful ACS risk scores available however these have not undergone rigorous validation. This study suggests that these other scores may be potentially useful and should be further researched [4].

Literature is evident that GRACE Score can predict better for high risk of mortality among NSTEMI cases. But still TIMI risk assessment is more in practice. So we aimed to conduct this study to implement the use of more appropriate and accurate method in future to be used as first line diagnostic tool in emergency cases to predict the outcome of NSTEMI cases. This will also help us to get local magnitudes as well as will help us to improve our clinical practice and knowledge.

\section{Objective}

The objective of this study is to compare the diagnostic accuracy of TIMI versus GRACE for prediction of death in patients presenting with Acute Non-ST elevation Myocardial Infarction.

\section{Materials and Methods}

This Case control study was conducted at Department of Cardiology, CPEIC, Multan for 6 months. Sample size of 372 patients is calculated with $95 \%$ confidence interval, $9 \%$ margin of error and taking expected percentage of NSTEMI i.e. $64.5 \%$ and sensitivity and specificity of TIMI i.e. $75 \%$ and $86 \%$ respectively, for prediction of death in patients presenting with NSTEMI. Non-probability consecutive sampling was used to include the patients. Patients of age 40-80 years of either gender presenting with Acute NSTEMI. Acute NSTEMI was infarction without ST-segment elevation precordial discomfort in the last 48 hours, associated with at least one of the following characteristics: 1) positive myocardial necrosis marker, defined as Troponin $\mathrm{T} \geq 0.01$ ug/l, which corresponds to values $>99$ thpercentile of the normal reference population; 2) ischemic electrocardiographic alterations, consisting of T-wave inversion $\left({ }^{3} 0.1 \mathrm{mV}\right)$ or transient ST-segment depression $\left({ }^{3} 0.05 \mathrm{mV}\right)$; 3) previously documented coronary artery disease, defined by a history of myocardial infarction or previous angiography demonstrating coronary obstruction $\geq 50 \%$. Risk of Death on TIMI: If TIMI Risk score was $>5$, then cases were labeled as high risk for death. Risk of Death on GRACE: If GRACE score was $>172$, then cases were labeled as high risk for death. Patients with medical record of intervention for previous $\mathrm{MI}$ i.e. PCI or CABG, valvular heart diseases. All patients assessed according to given scores in the two scoring system i.e. TIMI risk score and GRACE score. Then patients were labeled as high or low risk for death. Patients followed up during hospital stay for 7 days. During hospital stay, if patient would die, death was labeled. Data was collected by using pre-designed proforma. Data was entered and analyzed by SPSS version 20 . All quantitative variables like age were described by using mean and SD. All qualitative variables gender and death was described by using frequency and percentage. $2 \times 2$ tables were generated to measure the sensitivity, specificity, PPV, NPV and diagnostic accuracy of TMI Risk score and GRACE Score for prediction of death in NSTEMI patients.

\section{Results}

The mean age of the patients was $55.73 \pm 9.78$ years. In our study $61.83 \%$ patients were males and $38.17 \%$ patients were females. The male to female ratio of the patients was 1.6:1. Diabetes was found in 145(39\%) patients, smoking in 53(14.2\%) patients and hypertension in $174(46.8 \%)$ patients (Table 1). The mean TIMI score of the patients was $4.19 \pm 1.86$. The mean GRACE score of the patients was $132.77 \pm 52.73$. The study results showed that the death occurred in $46.77 \%$ patients and recovered patients were $53.23 \%$ patients (Table 2 ). 
The sensitivity of TIMI risk was $97.7 \%$ with specificity of $92.93 \%$. The PPV value of TIMI risk score was $92.39 \%$ and NPV value was $97.87 \%$. The diagnostic accuracy of TIMI risk was $95.16 \%$ (Table 3). The sensitivity of GRACE risk was 100\% with specificity of $95.96 \%$. The PPV value of GRACE risk score was $95.6 \%$ and NPV value was $100 \%$. The diagnostic accuracy of GRACE risk was $97.85 \%$ (Table 4 ).

\section{Discussion}

Global Registry of Acute Coronary Events (GRACE) and Thrombolysis in Myocardial Infarction (TIMI) risk scores have been widely used for prognosis predicting in patients with ACS [4-6]. In our study the death occurred in $46.77 \%$ patients. In this study the sensitivity of TIMI risk was $97.7 \%$ with specificity of $92.93 \%$ and the diagnostic accuracy was $95.16 \%$, similarly the sensitivity of GRACE risk was $100 \%$ with specificity of $95.96 \%$ and the diagnostic accuracy was $97.85 \%$. Some of the studies are discussed below showing the results on favor of our study as, the Portuguese study by Goncalves et al. [14], demonstrated the superiority of the GRACE score when compared to the TIMI score with a difference of 0.12 in C-statistics for the combination of death and in-hospital infarction [7]. There are other potentially useful ACS risk scores available however these have not undergone rigorous validation. This study suggests that these other scores may be potentially useful and should be further researched [4]. A study by Kozieradzka et al. [8], compared these scores in ST-segment elevation myocardial infarction and observed similar discriminatory ability. However, these authors did not analyze score calibration. In addition, that study analyzed long-term outcomes (fiveyear evolution).

The results of Erik P Hess et al. [9], meta-regression analysis indicated a strong linear relation between TIMI risk score and the short-term incidence of cardiac events. The incidence of cardiac events in the lowest risk stratum (TIMI score of zero) was $1.8 \%$; the sensitivity was $97.2 \%$ and specificity was $25.0 \%$ at this decision threshold. One more study by Hang Zhu et al. [10], presented that both GRACE and TIMI were adoptable in clinical risk stratification and prognosis of female patients with NSTE-ACS

\begin{tabular}{|c|c|}
\hline Table 1: Baseline characteristics of patients. \\
\hline Age & $55.73 \pm 9.78$ \\
\hline Gender $(m / f)$ & $38.2 \% / 61.8 \%$ \\
\hline Diabetes & $145(39 \%)$ \\
\hline Smoking & $53(14.2 \%)$ \\
\hline Hypertension & $174(46.8 \%)$ \\
\hline
\end{tabular}

Table 2: Descriptive statistics of TIMI score.

\begin{tabular}{|c|c|}
\hline TIMI score & $4.19 \pm 1.86$ \\
\hline GRACE score & $132.77 \pm 52.73$ \\
\hline Death occurred & $46.77 \%$ \\
\hline
\end{tabular}

Table 3: Comparison of TIMI risk with death of the patients.

\begin{tabular}{|c|c|c|c|c|}
\hline & & \multicolumn{2}{|c|}{ Death } & \multirow{2}{*}{ Total } \\
\hline & & Yes & No & \\
\hline \multirow{2}{*}{ TIMI risk } & High risk & 170 & 14 & 184 \\
\hline & Low risk & 4 & 184 & 188 \\
\hline \multicolumn{2}{|c|}{ Total } & 174 & 198 & 372 \\
\hline
\end{tabular}

Sensitivity: 97.7\%, Specificity: 92.93\%, PPV: 92.39\%, NPV: 97.87\% and Diagnostic Accuracy: 95.16\%

Table 4: Comparison of GRACE risk with death of the patients.

\begin{tabular}{|c|c|c|c|c|}
\hline & & \multicolumn{2}{|c|}{ Death } & \multirow{2}{*}{ Tota } \\
\hline & & Yes & No & \\
\hline \multirow{2}{*}{ GRACE risk } & High risk & 174 & 8 & 182 \\
\hline & Low risk & 0 & 190 & 190 \\
\hline \multicolumn{2}{|c|}{ Total } & 174 & 198 & 372 \\
\hline
\end{tabular}

Sensitivity: 100\%, Specificity: 95.96\%, PPV: 95.6\%, NPV: 100\% and Diagnostic Accuracy: $97.85 \%$. 
at different age groups. a study conducted in Brazil, has found that GRACE score has $50 \%$ sensitivity and $98 \%$ specificity for prediction of high risk for death in NSTEMI patients as compared to TIMI Risk score(sensitivity $=75 \%$, specificity=86\%). The authors concluded that although the scores show similar discriminatory capacity for hospital death, the GRACE score had better calibration than TIMI. These findings need to be validated populations of different risk profiles [11].

One more study by Ender Öner et al. [12], resulted that GRACE score showed good discriminatory capacity between the patients with and without a high-risk $(>33)$ SYNTAX score, with an area under the ROC curve of 0.804 (CI $0.6600 .948, p=0.002$ ); however, the TIMI score showed no predictive capacity and had an area under the ROC curve of 0.532 (CI 0.358- 0.749, p=0.749). A study by G. Ramsay et al. [13], described that the Both GRACE $(\mathrm{p}<0.001)$ and TIMI scores $(\mathrm{p}<0.001)$ predicted death/MI/ revascularization (and the composite including re-admission), but the GRACE score was superior to the TIMI score for predicting major cardiac events $(\mathrm{z}=2.05)$, and both scores were superior to clinical evaluation (ROC areas $0.82,0.74$ and 0.55 respectively).

Emad Abu-Ass et al. [14], revealed in their study that the GRACE risk score for predicting death within 6 months of hospital discharge was validated and can be used in patients with ACS. It would be wise to include the GRACE risk score in the medical records of these patients. Two more studies presented that The GRACE score has shown a greater prognostic value as compared with that of the TIMI score $[15,16]$.

\section{Conclusion}

Our study results concluded that both the TIMI risk and GRACE risk are good predictor of death in patients presenting with Acute Non-ST elevation Myocardial Infarction with higher sensitivity and diagnostic accuracy. However the GRACE risk showed more accurate results as compared to TIMI risk.

\section{References}

1. Hamm CW, Bassand JP, Agewall S, Bax J, Boersma E, et al. ESC Guidelines for the management of acute coronary syndromes in patients presenting without persistent ST-segment elevation. European Heart Journal. 2011; 32: 2999-3054. Ref.: https://goo.gl/WfY3zj

2. Gurm HS, Gore JM, Anderson FA, Wyman A, Fox KA, et a. Comparison of acute coronary syndrome in patients receiving versus not receiving chronic dialysis (from the Global Registry of Acute Coronary Events [GRACE] Registry). Am J Cardiol. 2012; 109: 19-25. Ref.: https://goo.gl/ABVHSK

3. Amin ST, Morrow DA, Braunwald E, Sloan S, Contant C, et al. Dynamic TIMI risk score for STEMI. J Am Heart Assoc. 2013; 2: e003269. Ref.: https://goo.gl/RnTeiE

4. D'Ascenzo F, Biondi-Zoccai G, Moretti $\mathrm{C}$, Bollati $\mathrm{M}$, Omedè $\mathrm{P}$, et al. TIMI, GRACE and alternative risk scores in Acute Coronary Syndromes: a meta-analysis of 40 derivation studies on 216,552 patients and of 42 validation studies on 31,625 patients. Contemp Clin Trials. 2012; 33: 507-514. Ref.: https://goo.gl/2WRnz1

5. Goldberg RJ, Gore JM, Alpert JS, Dalen JE. Recent changes in attack and survival rates of acute myocardial infarction (1975 through 1981): the Worcester Heart Attack Study. JAMA 1986; 255: 2774-2779. Ref.: https://goo.gl/X9s6tA

6. Bata IR, Gregor RD, Eastwood BJ, Wolf HK. Trends in the incidence of acute myocardial infarction between 1984 and 1993-The Halifax County MONICA Project. Can J Cardiol. 2000; 16: 589-595. Ref.: https://goo.gl/iCLfmd

7. Benter P, Gailani M, Gross P. Die Behandlung des akuten Koronarsyndroms ohne ST-Streckenelevation Neue Aspekte für die Koronarintervention. Clinical Research in Cardiology Supplements. 2008; 3: 7177. Ref.: https://goo.gl/QuU2sr

8. Van de Werf F, Ardissino D, Betriu A, Cokkinos DV, Falk E, et al. Management of acute myocardial infarction in patients presenting with ST-segment elevation. European Heart Journal. 2003; 24: 2866. Ref.: https://goo.gl/d2imY9

9. Birkhead J, Walker L, Pearson M, Weston C, Cunningham A, et al. Improving care for patients with acute coronary syndromes: initial results from the National Audit of Myocardial Infarction Project (MINAP). Heart. 2004; 90: 1004-1009. Ref.: https://goo.gl/GzRegL 
10. Eagle KA, Lim MJ, Dabbous OH, Pieper KS, Goldberg RJ, et al. A validated prediction model for all forms of acute coronary syndrome: estimating the risk of 6-month postdischarge death in an international registry. JAMA. 2004; 291: 2727-2733. Ref.: https://goo.gl/FBuCYP

11. Correia LC, Garcia G, Kalil F, Ferreira F, Carvalhal M, et al. Prognostic value of TIMI score versus GRACE score in ST-segment elevation myocardial infarction. Arquivos brasileiros de cardiologia. 2014; 103: 98-106. Ref.: https://goo.gl/V9eJLh

12. Terkelsen CJ, Lassen JF, Nørgaard BL, Gerdes JC, Jensen T, et al. Mortality rates in patients with STelevation vs. non-ST-elevation acute myocardial infarction: observations from an unselected cohort. Eur Heart J. 2005; 26: 18-26. Ref.: https://goo.gl/HpkzX8

13. GRACE Investigators. Rationale and design of the GRACE (Global Registry of Acute Coronary Events) Project: a multinational registry of patients hospitalized with acute coronary syndromes. Am Heart J. 2001; 141: 190-199. Ref.: https://goo.gl/in5nmw

14. Volmink J, Newton J, Hicks $\mathrm{N}$, Sleight $\mathrm{P}$, Fowler $\mathrm{G}$, et al. Coronary event and case fatality rates in an English population: results of the Oxford myocardial infarction incidence study. Heart. 1998; 80: 4044. Ref.: https://goo.gl/YwEMKD

15. Bahit MC, Granger CB, Wallentin L. Persistence of the prothrombotic state after acute coronary syndromes: implications for treatment. Am Heart J. 2002; 143: 205-216. Ref.: https://goo.gl/ikJQ55

16. Davies MJ. The pathophysiology of acute coronary syndromes. Heart. 2000; 83: 361-366. Ref.: https://goo.gl/ZktyVc 